\title{
Does referral to specialist paediatric palliative care services reduce hospital admissions in oncology patients at the end of life?
}

\author{
L K Fraser ${ }^{\star}, 1$, M van Laar ${ }^{2}$, M Miller $^{3}$, J Aldridge ${ }^{3}$, P A McKinney ${ }^{2}, \mathrm{R}$ C Parslow ${ }^{2}$ and R G Feltbower ${ }^{2}$ \\ ${ }^{1}$ Department of Health Sciences, University of York, Room A/TB214, Area 4, Seebohm Rowntree Building, York, YO10 5DD, UK; \\ ${ }^{2}$ Paediatric Epidemiology Group, Division of Epidemiology, University of Leeds, Leeds, LS2 9NL, UK and '3artin House Children's \\ Hospice, Grove Road, Wetherby, LS23 6TX, UK
}

Background: Despite advances in the treatment of childhood cancer, some children continue to die from their disease. This study aimed to assess the impact of specialist paediatric palliative care services (SPPCSs) on the number of hospital admissions in children who subsequently died from cancer in Yorkshire, UK.

Methods: An extract of patients aged 0-19 years from the Yorkshire Specialist Register of Cancer in Children and Young People (YSRCCYP) diagnosed from 1990 to 2009 were linked to inpatient hospital episodes data and a SPPCS database. Deaths were included if they occurred before 31 August 2011. Differences in hospital admission patterns were assessed using negative binomial regression and presented as incidence rate ratios (IRRs).

Results: Of 2508 children on the YSRCCYP, 657 (26\%) had died by the censoring date. A total of 211 children had been referred to the local SPPCS, of whom 182 (86\%) had subsequently died. Referral to SPPCS was associated with a significant reduction in the rate of planned hospital admissions (IRR $=0.60,95 \% \mathrm{Cl} 0.43-0.85$ ). Central nervous system tumours showed significant decreases for all planned and emergency admissions compared with all other diagnostic groups.

Conclusion: Referral to SPPCS significantly reduced the number of planned hospital admissions for children and young people with cancer before their death, which are often integral to paediatric oncology treatment regimens. Overall, our findings show that SPPCS have a role in reducing hospital admissions during end of life care of paediatric cancer patients with potential personal, social and economic benefits.

Specialist Paediatric Palliative Care Services (SPPCSs) have been developed rapidly over the last three decades, but as a medical subspecialty are still in their infancy. Despite advances in the treatment of childhood cancer, some children continue to die from their disease, with cancer being the second most common cause of death in children and young people aged 0-19 years of age (Office for National Statistics, 2005). SPPCSs are therefore an important component of children's oncology services, and ensuring that equitable access to palliative care services is one of the aims set out in the Improving Outcomes Guidance published in 2005 (National Institute for Health and Clinical Excellence, 2005), and were highlighted again by the Department of Health as an important component of the Oncology and Malignant Haematology specialised paediatric services in 2008 (Department of Health, 2008b). In the United Kingdom, approximately a third of children and young people who die from cancer have been referred to SPPCS before death and this proportion has not changed since 1990 (Fraser et al, 2011b). Referral to SPPCS for children with life-limiting conditions has resulted in more children dying in the community (home or hospice) than hospital (Fraser et al, 2011a). SPPCS vary across the world, for example, services were available in $58 \%$ of Children's Oncology Group institutions, the majority of which are in North America, but were only used by a small minority of patients (Johnston et al, 2008), and in Taiwan, only $7.2 \%$ of children who 
subsequently died from cancer had been cared for by a hospice (Tang et al, 2011). In two states in the United States, a survey of paediatricians found that $74 \%$ of them were reluctant to refer patients to SPPCS, with the main reasons being related to family reluctance to accept palliative care, families viewing palliative care as giving up and difficulty in determining the right time to refer to palliative care (Knapp and Thompson, 2012).

Children with cancer who are dying are frequently admitted to hospital which can be disrupting and distressing for the child and their family. A reduction in these events would potentially have clinical, social and economic benefits, but, currently, no data are available on the pattern or numbers of hospital admissions that occur during end of life care, and no literature has been published on whether the involvement of SPPCS might reduce hospital inpatient admissions and benefit this group. Yorkshire, UK, has a unique combination of overlapping data sets on childhood cancers, hospital admissions and children accessing SPPCS that has allowed us to measure the impact of SPPCS on the number of hospital admissions in children before their death from cancer.

\section{MATERIALS AND METHODS}

The cohort for this study was extracted from the Yorkshire Specialist Register of Cancer in Children and Young People (YSRCCYP) and includes patients aged 0-19 years diagnosed from 1990 to 2009. Only individuals resident in the former Yorkshire Regional Health Authority (Yorkshire) were included to have comparative 'catchment' areas to the SPPCS.

The YSRCCYP contains clinical and demographic information on all children and young people diagnosed with cancer in Yorkshire. Data used in these analyses included age at diagnosis, gender, date of death, deprivation category, year of diagnosis and International Classification of Childhood Cancer (ICCC) diagnostic groups (Steliarova-Foucher et al, 2005). Date of death recorded on the YSRCCYP is obtained through automated death notifications from the Office for National Statistics death registration records. Deprivation category was determined using the Townsend deprivation score, which is based on unemployment, non-car ownership, non-home ownership and household overcrowding (Phillimore et al, 1994). Townsend deprivation scores were derived by English census output area of residence at time of diagnosis using 2001 census data, and were split into five categories from least deprived to most deprived. The ICCC groups were aggregated for certain analyses to avoid small numbers into: leukaemia (I), lymphoma (II), central nervous system (CNS) tumours (III) and other solid tumours (IV-XII). Ethnic group was assigned from the linked data (see below).

Linked data. The SPPCS in the former Yorkshire Regional Health Authority is provided by Martin House Childrens' Hospice (2012). Martin House Children's Hospice has been caring for children and young adults (aged up to 35 years) with life-limiting conditions since 1987. In this SPPCS, medical support was slowly increased from part to full time in house cover (between 1987 and 2004), and a full time consultant in Paediatric Palliative Medicine was appointed from 2004 onwards.

Using data collected by the SPPCS, any individual who had been accepted for care by the SPPCS was flagged on the YSRCCYP.

In addition to this, inpatient hospital episode statistics (HES) data were linked to the YSRCCYP. HES data contains all admissions to National Health Service hospitals in England (NHS Information Centre, 2011), and although this data has been recorded for inpatient admissions since 1989, it was not deemed to be complete enough for research purposes until 1996. Thus, all individuals registered on the YSRCCYP who were alive from 1 January 1996 onwards were linked to inpatient HES data.

Data manipulation. The HES data provide details on individual 'finished consultant episodes' (FCEs). An FCE is not the same as a hospital admission; one hospital admission can comprise one or more FCEs if a patient is cared for by more than one consultant during their admission (NHS Information Centre, 2011). Therefore, continuous inpatient spells (CIPSs) were constructed for each patient, each CIPS representing each unique admission for every patient. A detailed description of the algorithm used to create the CIPS is given in the user guide by the National Centre for Health Outcomes Development (2009).

Planned hospital admissions are the basis of treatment for most paediatric cancer patients, so in order to assess the potential impact of palliative care involvement, each hospital admission was classified as planned (elective) or emergency (all other admission codes, $>97 \%$ were emergency admissions in this cohort) using the admission method codes recorded in the first FCE in each CIPS.

A 'proxy date of referral' for patients who had died and were not referred for SPPCS was estimated by simulating the time from diagnosis to referral from a negative binomial distribution based on those patients who were referred to SPPCS (Figure 1). The simulation was performed by ICCC group, and summaries of the referral time periods are given in Table 1 . This allowed the number
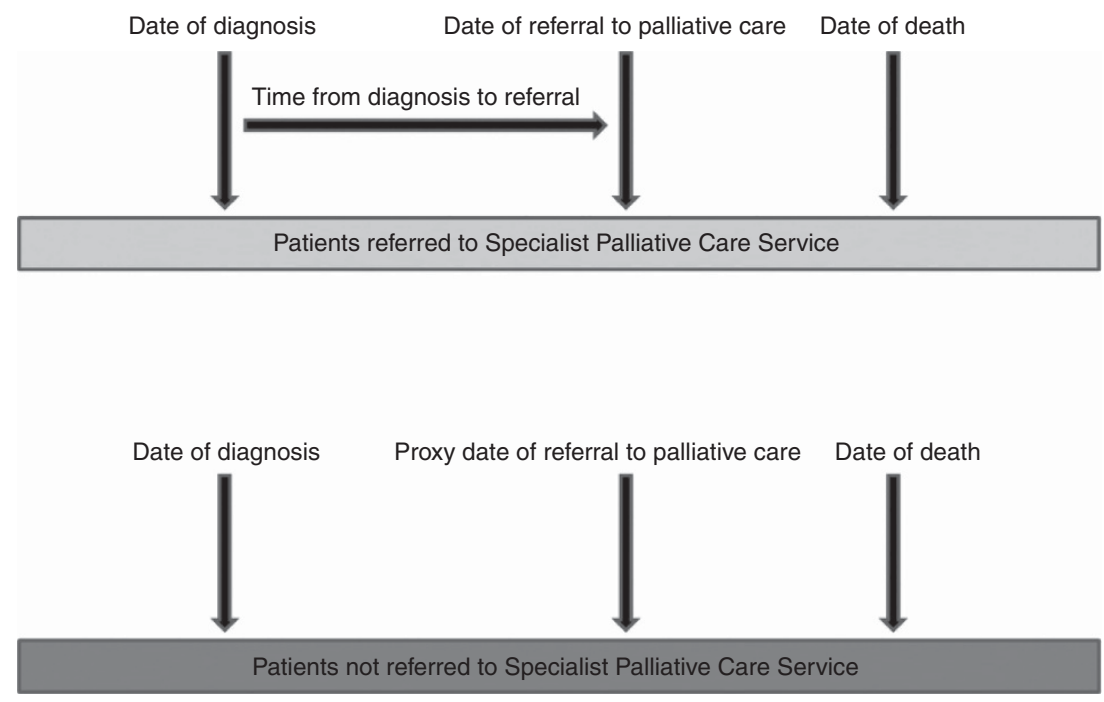

Figure 1. Calculation of time to referral. 
of hospital admissions (total, planned and emergency) for this time period to be calculated for each individual. This method was preferred to simply analysing the rate of admissions in a predefined period (for example, 3 or 6 months before death) as the disease trajectories varied widely between the ICCC groups.

Assignment of ethnic category was achieved using ethnicity as recorded within HES data. Ethnicity within HES should be self-reported by the patient. Individuals with multiple ethnicity codes were assigned their most commonly reported ethnicity group unless the most common ethnicity was 'not known' (NCIN, 2009). The 16 census ethnic groups (Census, 2001) were merged into four combined groups to avoid very small numbers in some categories: White (White: British; White: Irish; White: Other White), South Asian (Asian or Asian British: Indian; Asian or Asian British: Pakistani; Asian or Asian British: Bangladeshi; Asian or Asian British: Other Asian), Black (Black or Black British: Black Caribbean; Black or Black British; Black African; Black or Black British: Other Black) and other ethnic groups (Mixed: White and Black Caribbean; Mixed: White and Black African; Mixed: White and Asian; Mixed: other mixed, chinese and other ethnic group).

Statistical analyses. The clinical and demographic variables were described for the whole cohort and subdivided into those who had died without referral to SPPCS and those who had been referred for SPPCS. As no previous literature exists on hospital admissions occurring during end of life care for childhood cancer, the variables included within the analysis as mentioned previously were chosen based on standard variables used within the literature of survival of childhood cancer (Wilkinson et al, 2001; Magnani et al, 2006; Basta et al, 2011; van Laar et al, 2012). The impact of referral on SPPCS was explored using negative binomial regression modelling (which was chosen over Poisson regression due to overdispersion), with the total number of hospital admissions as the main outcome. We modelled hospital admission rates by including each person's postreferral follow-up time in the model as an exposure term. Two further negative binomial regression models were run with number of planned hospital admissions and the total number of emergency hospital admissions during the same time period.

Ethics. The YSRCCYP is a member of the UK Association of Cancer Registries, which currently holds section 251 permission

\begin{tabular}{|c|c|c|c|c|}
\hline $\begin{array}{l}\text { ICCC } \\
\text { classification }\end{array}$ & $\begin{array}{c}\text { Number of } \\
\text { Patients }\end{array}$ & $\begin{array}{l}\text { Median time to } \\
\text { referral (days) }\end{array}$ & & \\
\hline Leukaemia & 32 & 518 & 363 & 995 \\
\hline Lymphoma & 14 & 368 & 189 & 595 \\
\hline CNS & 84 & 262 & 110 & 1206 \\
\hline Neuroblastoma & 19 & 319 & 157 & 647 \\
\hline Retinoblastoma & 0 & - & - & - \\
\hline Renal & 6 & 390 & 78 & 1205 \\
\hline Hepatic & 3 & 122 & 49 & 339 \\
\hline Bone & 18 & 561 & 206 & 678 \\
\hline Soft tissue & 29 & 273 & 194 & 562 \\
\hline Germ cell & 2 & 169 & 125 & 212 \\
\hline Other epithelial $^{a}$ & 3 & 582 & 109 & 824 \\
\hline Other & 0 & - & - & - \\
\hline \multicolumn{5}{|c|}{$\begin{array}{l}\text { Abbreviations: } \mathrm{CNS}=\text { central nervous system; ICCC = International Classification of Child- } \\
\text { hood Cancer; } \mathrm{IQR}=\text { inter quartile range. } \\
{ }^{\mathrm{a}} \text { Classification includes: adrenocortical carcinomas, thyroid carcinomas, nasopharyngeal } \\
\text { carcinomas, malignant melanomas and other unspecified carcinomas. }\end{array}$} \\
\hline
\end{tabular}

from the National Information Governance Board to hold and process data on children and young people with cancer without obtaining consent. Ethical approval for this study was obtained from the Bradford NHS Ethics Committee (09/H1302/81).

\section{RESULTS}

There were 2508 individual patients diagnosed between 1990 and 2009, aged 0-19 years and registered on the YSRCCYP (Table 2). Of these, $26.2 \%(n=657)$ had died before the extract date $(31$ August 2011). In total, 211 children had been referred to SPPCS, of which 182 had died before the extract date (Figure 2). Therefore, $27.7 \%$ of those who had died were referred to SPPCS before death.

The groups (those who died and had been referred $(n=182)$ compared with those who died and were not referred to SPPCS $(n=475))$ did not differ significantly in terms of gender, deprivation category, ethnicity or year group of diagnosis. The age groups did differ significantly with a smaller percentage in the oldest age group referred to SPPCS. The groups also differed in terms of ICCC diagnostic category with CNS tumours forming the largest subgroup in those referred to SPPCS (Table 2).

The linkage rate to the HES data set was $89.1 \%$ in this cohort. Those who did not link tended to be male, were diagnosed under the age of 5 and were diagnosed towards the beginning of the study period. This linkage rate did not differ significantly between the SPPCS group and the remainder of the cohort (Table 3). The mean number of total hospital admissions between referral and death was higher in the group not referred to SPPCS (14.1vs 4.7, $t=4.11$, $P<0.001)$ as were the number of planned hospital admissions between referral and death (10.0 vs 2.6, $t=4.01, P<0.001)$, and the mean number of emergency admissions during this time period (4.1 vs $2.1, t=2.97, P=0.003$ ).

The results from the adjusted negative binomial model (Table 4) showed that patients referred to SPPCS had significantly lower planned admission rates compared with those who were not referred (incidence rate ratio (IRR) $=0.60$, 95\% CI $0.43-0.85$ ), however, there was no significant effect of referral on overall admission rates or emergency admission rates. Children diagnosed at an older age had significantly fewer hospital admission rates by $3 \%($ IRR $=0.97,95 \%$ CI $0.95-1.00)$ for total admissions. This effect was also seen in planned hospital admissions, but not for emergency hospital admissions. Children with CNS tumours had significantly fewer total hospital admissions compared with those with leukaemia (IRR $=0.41,95 \%$ CI $0.28-0.61)$, which was consistent in both emergency and planned hospital admissions. In addition, the models show a significant increase in total emergency and planned hospital admissions for every year increase over the study period, 1990-2009 (total admissions IRR $=1.09$, 95\% CI 1.06-1.12).

\section{DISCUSSION}

This novel study has shown that although less than a third of children and young people who died of their cancer were referred to a SPPCS, a referral was significantly associated with fewer planned hospital inpatient admissions, by $40 \%$ on average. This is a particularly significant finding in the general context of increasing hospitalisation rates for survivors of childhood and adolescent cancer and was seen consistently across all four major diagnostic groups. An explanation for the relatively small proportion of people referred to SPCCS is unclear; possible reasons might include family reluctance to accept palliative care and a lack of education about SPCCS (Knapp and Thompson, 2012), or ease of access and proximity to Martin House. Hospital admissions are 
Table 2. Clinical and demographic information

Yorkshire specialist register of cancer in children and young people

Martin house childrens' hospice

\begin{tabular}{|c|c|c|c|c|c|c|c|c|}
\hline & Total & col \% & Died & col \% & Total & col \% & Died & col \% \\
\hline Total & 2508 & 100 & 657 & 100 & 211 & 100 & 182 & 100 \\
\hline \multicolumn{9}{|l|}{ Gender } \\
\hline Male & 1551 & 61.8 & 481 & 73.2 & 153 & 72.5 & 132 & 72.5 \\
\hline Female & 957 & 38.2 & 176 & 26.8 & 58 & 27.5 & 50 & 27.5 \\
\hline \multicolumn{9}{|c|}{ Age group at diagnosis } \\
\hline $0-4$ years & 932 & 37.2 & 253 & 38.5 & 91 & 43.1 & 73 & 40.1 \\
\hline $5-9$ years & 510 & 20.3 & 125 & 19.0 & 57 & 27.0 & 50 & 27.5 \\
\hline $10-14$ years & 533 & 21.2 & 147 & 22.4 & 49 & 23.2 & 45 & 24.7 \\
\hline $15-19$ years & 533 & 21.2 & 132 & 20.1 & 14 & 6.6 & 14 & 7.7 \\
\hline
\end{tabular}

Ethnic category

\begin{tabular}{|c|c|c|c|c|c|c|c|c|}
\hline White & 1676 & 66.8 & 328 & 49.9 & 125 & 59.2 & 100 & 54.9 \\
\hline Mixed & 12 & 0.5 & 3 & 0.5 & 2 & 0.9 & 2 & 1.1 \\
\hline South Asian & 176 & 7.0 & 42 & 6.4 & 6 & 2.8 & 6 & 3.3 \\
\hline Black & 16 & 0.6 & 3 & 0.5 & 2 & 0.9 & 1 & 0.5 \\
\hline Other & 31 & 1.2 & 11 & 1.7 & 7 & 3.3 & 6 & 3.3 \\
\hline Not known ${ }^{a}$ & 597 & 23.8 & 270 & 41.1 & 69 & 32.7 & 67 & 36.8 \\
\hline
\end{tabular}

Deprivation category

\begin{tabular}{|c|c|c|c|c|c|c|c|c|}
\hline 1 (least deprived) & 480 & 19.1 & 134 & 20.4 & 34 & 16.1 & 28 & 15.4 \\
\hline 2 & 514 & 20.5 & 120 & 18.3 & 41 & 19.4 & 36 & 19.8 \\
\hline 3 & 443 & 17.7 & 106 & 16.1 & 41 & 19.4 & 36 & 19.8 \\
\hline 4 & 407 & 16.2 & 112 & 17.1 & 41 & 19.4 & 34 & 18.7 \\
\hline 5 (most deprived) & 663 & 26.4 & 185 & 28.2 & 54 & 25.6 & 48 & 26.4 \\
\hline Not Known & 1 & 0.0 & 0 & 0 & 0 & 0 & 0 & 0 \\
\hline \multicolumn{9}{|c|}{ ICCC diagnostic category } \\
\hline Leukaemia & 703 & 28.0 & 170 & 25.9 & 33 & 15.6 & 24 & 13.2 \\
\hline Lymphoma & 369 & 14.7 & 61 & 9.3 & 14 & 6.6 & 13 & 7.1 \\
\hline CNS & 508 & 20.3 & 164 & 25.0 & 84 & 39.8 & 72 & 39.6 \\
\hline Neuroblastoma & 145 & 5.8 & 66 & 10.0 & 19 & 9.0 & 18 & 9.9 \\
\hline Retinoblastoma & 58 & 2.3 & 1 & 0.2 & 0 & 0 & 0 & 0 \\
\hline Renal & 119 & 4.7 & 19 & 2.9 & 6 & 2.8 & 4 & 2.2 \\
\hline Hepatic & 23 & 0.9 & 8 & 1.2 & 3 & 1.4 & 3 & 1.6 \\
\hline Bone & 128 & 5.1 & 57 & 8.7 & 18 & 8.5 & 18 & 9.9 \\
\hline Soft tissue & 209 & 8.3 & 82 & 31.8 & 29 & 13.7 & 26 & 0.5 \\
\hline Germ Cell & 178 & 7.1 & 15 & 2.3 & 2 & 0.9 & 1 & 0.5 \\
\hline Other epithelial & 64 & 2.6 & 12 & 1.8 & 3 & 1.4 & 3 & 1.6 \\
\hline Other & 4 & 0.2 & 2 & 0.3 & 0 & 0 & 0 & 0 \\
\hline \multicolumn{9}{|l|}{ Year diagnosis } \\
\hline 1990-1994 & 618 & 24.6 & 219 & 33.3 & 63 & 29.9 & 57 & 31.3 \\
\hline 1995-1999 & 595 & 23.7 & 186 & 28.3 & 60 & 28.4 & 53 & 29.1 \\
\hline $2000-2004$ & 667 & 26.6 & 144 & 21.9 & 54 & 25.6 & 44 & 24.2 \\
\hline 2005-2009 & 628 & 25.0 & 108 & 16.4 & 34 & 16.1 & 28 & 15.4 \\
\hline
\end{tabular}

considered socially disruptive and financially draining for children and families, and more hospital admissions have been associated with distress in fathers of childhood cancer patients (Sloper, 2000) and a higher risk of poor adjustment in siblings (Sloper and While, 1996). Delivery of appropriate end of life care that reduces the frequency of these events would be beneficial to patients and their families, as well as the NHS. Martin House offer a range of services that could help reduce hospital admissions, including a 24-h on-call medical service, with the ability for home visits as well as the ability to manage symptoms as inpatients when needed.

The World Health Organisation definition of paediatric palliative care states that 'It begins when illness is diagnosed, and continues regardless of whether or not a child receives treatment directed at the disease.' However, the adult palliative care model, 


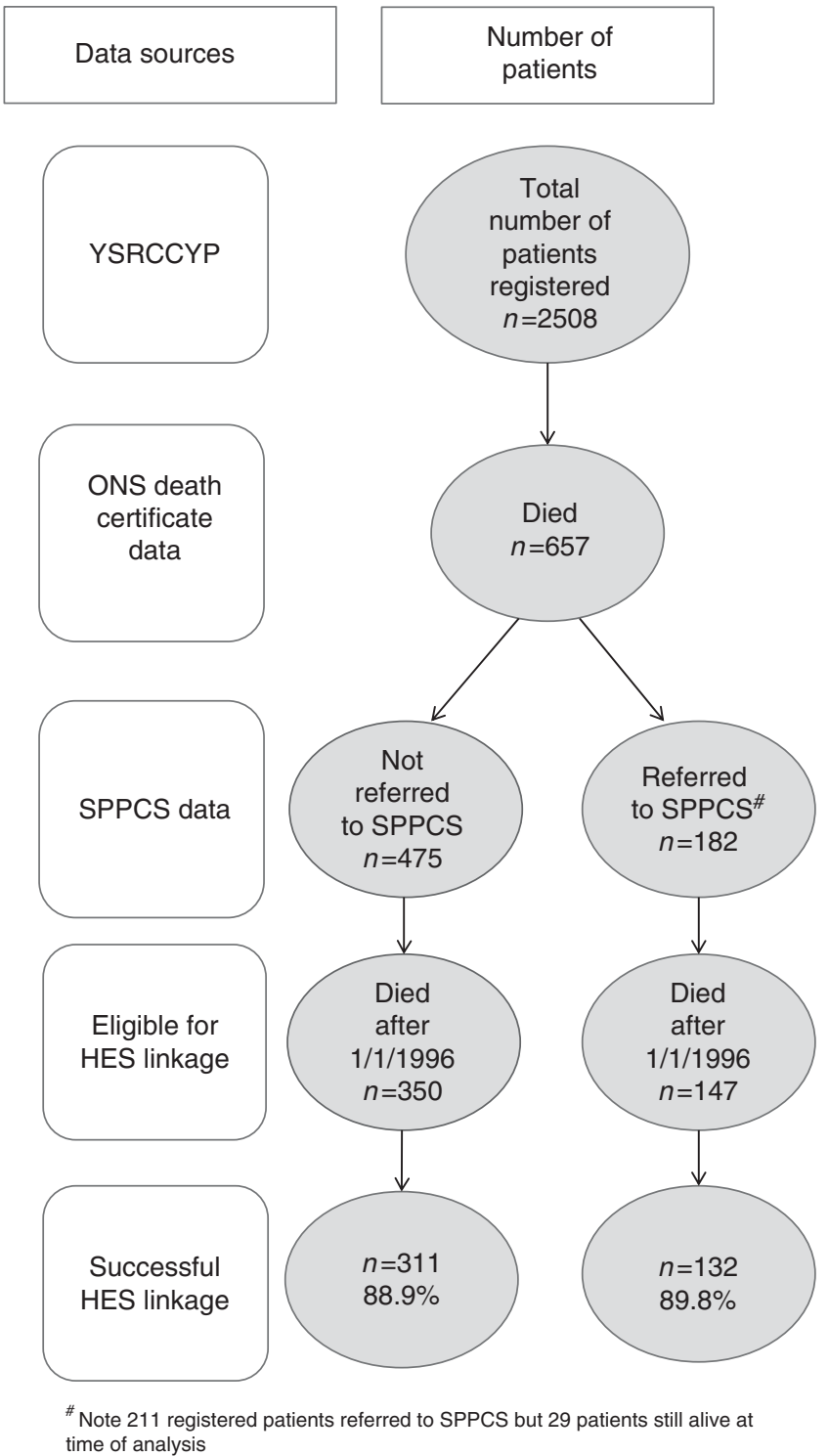

Figure 2. Data sources.

whereby palliative care is a phase that starts after disease-directed treatment has failed, tends to be followed in paediatric oncology patients. This may explain why the groups of patients who were not referred for SPPCS had significantly higher planned hospital admission rates than the SPPCS group, that is, they may still be receiving tumour-directed treatment, which could mean they are more likely to be admitted for side effects from treatment. A previous UK publication (Shah et al, 2011), which looked at the number of hospital episodes by place of death in children who died from cancer, showed those patients who died at home or in a hospice spent fewer days in hospital in the last 6 months of life than those who had died in hospital. Our results are consistent with these observations, but this was a descriptive analysis, and involvement of SPPCS was not known in these patients. The place of death was not available for the patients in the current study.

Children with CNS tumours had a significantly lower rate of admissions to hospital (whether planned or emergency) compared with leukaemia (by $60 \%$ on average). There are several reasons that may explain this finding. Inpatient treatment of CNS tumours is less likely than for leukaemia because the mainstay of leukaemia treatment is chemotherapy and as such there is a higher incidence of immunosupression and therefore an increased risk of febrile

\begin{tabular}{|c|c|c|c|}
\hline & YSRCCYP & $\begin{array}{l}\text { Not } \\
\text { referred to } \\
\text { SPPCS }\end{array}$ & $\begin{array}{l}\text { Referred to } \\
\text { SPPCS }\end{array}$ \\
\hline Total deaths & 657 & 475 & 182 \\
\hline Eligible for HES linkage & 497 & 350 & 147 \\
\hline \multirow[t]{2}{*}{ Successful linkage to HES } & $443(89.1 \%)$ & $311(88.9 \%)$ & $132(89.8 \%)$ \\
\hline & Mean (s.d.) & Mean (s.d.) & Mean (s.d.) \\
\hline $\begin{array}{l}\text { Total number of hospital } \\
\text { admissions between referral to } \\
\text { SPPCS and death }\end{array}$ & $11.3(22.7)$ & $14.1(25.8)$ & $4.7(10.3)$ \\
\hline $\begin{array}{l}\text { Number of planned hospital } \\
\text { admissions between referral to } \\
\text { SPPCS and death }\end{array}$ & $7.8(18.0)$ & $10.0(20.7)$ & $2.6(6.0)$ \\
\hline $\begin{array}{l}\text { Number of emergency hospital } \\
\text { admissions between referral to } \\
\text { SPPCS and death }\end{array}$ & $3.5(6.1)$ & $4.1(6.3)$ & $2.1(5.2)$ \\
\hline \multicolumn{4}{|c|}{$\begin{array}{l}\text { Abbreviations: HES = hospital episode statistics; SPPCS }=\text { Specialist Paediatric Palliative } \\
\text { Care Service; YSRCCYP = Yorkshire Specialist Register of Cancer in Children and Young } \\
\text { People. } \\
a_{P}<0.0001 \text { t-test. } \\
\mathbf{b}_{P=0.003 \text { t-test. }}\end{array}$} \\
\hline
\end{tabular}

neutropenia. Side effects from CNS tumours, such as vomiting or swelling, around the tumour in response to steroids can be managed at home, making inpatient treatments less likely for this group. CNS tumours are a heterogeneous group of tumours, including a spectrum of both low and high grade tumours, compared with a homogenous group of leukaemia patients who are treated on inpatient-intensive treatment protocols.

The trend in children diagnosed more recently having higher rates of hospital admissions may represent changes in practice, such as increased levels of therapy and the use of aggressive relapse treatments. Although this study was not designed to assess the health economics of hospital admissions vs SPPCS care, the reduction in hospitalisation rates for planned admissions associated with referral to SPPCS helps to ameliorate the impact of increasing admissions rates over time, and such reductions clearly would be financially beneficial to the NHS.

The Department of Health Children and Young People's Health Outcomes Forum has called for improved quality and availability of data on children with disability, life-limiting conditions and complex needs in which children with cancer are included (Lewis and Lenehan, 2012). This study provides valuable evidence for the benefit of the involvement of SPPCS in the care of the child dying from cancer. This information will also be useful for the Department of Health in England's Palliative Care Funding Review (Hughes-Hallet et al, 2011) and local commissioners (Craft and Killen, 2008; Department of Health, 2008a).

Strengths of this study include its population base, size and quality utilising 20 years of routinely collected data, but it is not without its limitations. Missing ethnicity data hampered any meaningful assessment of inequalities in relation to outcomes or service access by the ethnic group, and the availability of the HES data was restricted to the period from 1996 onwards.

The study relied on successful linkage of the HES and YSRCCYP data, as well as successfully flagging up of those referred to SPCCS on the YSRCCYP. Although both these methods were carried out using detailed linking approaches, typographical errors for some of the data could have led us to miss some patients. Although the linkage rate of HES to the YSRCCYP was high $(89.1 \%)$, there were some differences between those cases that 
Table 4. Negative binomial models with number of hospital admissions as the outcomes

\begin{tabular}{|c|c|c|c|c|c|c|c|c|c|c|c|c|}
\hline \multirow{3}{*}{$\begin{array}{l}\text { Variable } \\
\text { Age at Diagnosis (years) }\end{array}$} & \multicolumn{4}{|c|}{ Model A: total number of admissions } & \multicolumn{4}{|c|}{ Model B: emergency admissions } & \multicolumn{4}{|c|}{ Model C: planned admissions } \\
\hline & \multirow{2}{*}{$\begin{array}{l}\text { IRR } \\
0.97\end{array}$} & \multicolumn{2}{|c|}{$95 \% \mathrm{Cl}$} & \multirow{2}{*}{$\begin{array}{c}\boldsymbol{P} \text {-value } \\
0.019\end{array}$} & \multirow{2}{*}{$\begin{array}{l}\text { IRR } \\
0.98\end{array}$} & \multicolumn{2}{|c|}{$95 \% \mathrm{Cl}$} & \multirow{2}{*}{$\begin{array}{c}\boldsymbol{P} \text {-value } \\
0.170\end{array}$} & \multirow{2}{*}{\begin{tabular}{|l|} 
IRR \\
0.97
\end{tabular}} & \multicolumn{2}{|c|}{$95 \% \mathrm{Cl}$} & \multirow{2}{*}{$\begin{array}{c}\boldsymbol{P} \text {-value } \\
0.020\end{array}$} \\
\hline & & 0.95 & 1.00 & & & 0.96 & 1.01 & & & 0.94 & 0.99 & \\
\hline \multicolumn{13}{|l|}{ ICCC } \\
\hline $\begin{array}{l}\text { Leukaemia } \\
\text { Lymphoma } \\
\text { CNS } \\
\text { Other solid tumours }\end{array}$ & $\begin{array}{l}\text { REF } \\
0.79 \\
0.41 \\
0.84\end{array}$ & $\begin{array}{l}0.49 \\
0.28 \\
0.60\end{array}$ & $\begin{array}{l}1.28 \\
0.61 \\
1.18\end{array}$ & $\begin{array}{r}0.342 \\
<0.001 \\
0.323\end{array}$ & $\begin{array}{l}\text { REF } \\
0.95 \\
0.56 \\
0.85\end{array}$ & $\begin{array}{l}0.58 \\
0.37 \\
0.60\end{array}$ & $\begin{array}{l}1.56 \\
0.84 \\
1.22\end{array}$ & $\begin{array}{l}0.827 \\
0.005 \\
0.391\end{array}$ & \begin{tabular}{|l|} 
REF \\
0.71 \\
0.33 \\
0.85
\end{tabular} & $\begin{array}{l}0.41 \\
0.21 \\
0.57\end{array}$ & $\begin{array}{l}1.24 \\
0.52 \\
1.27\end{array}$ & $\begin{array}{r}0.235 \\
<0.001 \\
0.424\end{array}$ \\
\hline \multicolumn{13}{|l|}{ Gender } \\
\hline $\begin{array}{l}\text { Male } \\
\text { Female }\end{array}$ & $\begin{array}{l}\text { REF } \\
0.93\end{array}$ & 0.73 & 1.20 & 0.595 & $\begin{array}{l}\text { REF } \\
0.98\end{array}$ & 0.75 & 1.27 & 0.858 & $\begin{array}{l}\text { REF } \\
0.90\end{array}$ & 0.67 & 1.22 & 0.510 \\
\hline \multicolumn{13}{|l|}{ Referred to SPPCS } \\
\hline $\begin{array}{l}\text { No } \\
\text { Yes }\end{array}$ & $\begin{array}{l}\text { REF } \\
0.79\end{array}$ & 0.59 & 1.05 & 0.106 & $\begin{array}{l}\text { REF } \\
1.15\end{array}$ & 0.84 & 1.58 & 0.375 & $\begin{array}{l}\text { REF } \\
0.60\end{array}$ & 0.43 & 0.85 & 0.004 \\
\hline \multicolumn{13}{|l|}{ Deprivation category } \\
\hline $\begin{array}{l}1 \text { (least deprived) } \\
2 \\
3 \\
4 \\
5 \text { (most deprived) }\end{array}$ & $\begin{array}{l}\text { REF } \\
0.80 \\
0.74 \\
0.98 \\
1.02\end{array}$ & $\begin{array}{l}0.54 \\
0.50 \\
0.67 \\
0.71\end{array}$ & $\begin{array}{l}1.20 \\
1.10 \\
1.44 \\
1.46\end{array}$ & $\begin{array}{l}0.278 \\
0.132 \\
0.925 \\
0.913\end{array}$ & $\begin{array}{l}\text { REF } \\
0.87 \\
0.82 \\
1.12 \\
1.37\end{array}$ & $\begin{array}{l}0.57 \\
0.54 \\
0.74 \\
0.94\end{array}$ & $\begin{array}{l}1.32 \\
1.24 \\
1.68 \\
1.99\end{array}$ & $\begin{array}{l}0.508 \\
0.340 \\
0.601 \\
0.105\end{array}$ & $\begin{array}{l}\text { REF } \\
0.78 \\
0.69 \\
0.89 \\
0.89\end{array}$ & $\begin{array}{l}0.49 \\
0.44 \\
0.57 \\
0.59\end{array}$ & $\begin{array}{l}1.24 \\
1.09 \\
1.40 \\
1.35\end{array}$ & $\begin{array}{l}0.295 \\
0.116 \\
0.627 \\
0.582\end{array}$ \\
\hline Year of diagnosis & 1.09 & 1.06 & 1.12 & $<0.001$ & 1.10 & 1.06 & 1.13 & $<0.001$ & 1.09 & 1.06 & 1.13 & $<0.001$ \\
\hline
\end{tabular}

linked and those that did not. Cases less likely to link tended to be diagnosed towards the beginning of the study period, be under the age of 5 and be male. As the cohort of those referred to SPCCS was small, data were carefully interrogated to ensure matches were not missed based on simple typographical errors.

In order to compare the rate of admissions between those who were and were not referred to SPCCS, we used a proxy date for referral in patients who were not referred to SPCCS. A simulation approach to estimate the date of referral was adopted in an attempt to minimise any biases, as would be caused by simply using an average value, such as the mean or median. This approach was preferred to the option of looking at admissions in a specific time period towards the end of life (i.e., 6 months), because of the variations in disease trajectories between diagnostic groups.

We investigated inpatient hospital admissions but additional sources of hospital contact include outpatient visits and accident and emergency (A\&E) department attendances. This data have been collected more recently by the NHS, and future work should include an assessment of $\mathrm{A} \& \mathrm{E}$ usage among these patients.

\section{CONCLUSIONS}

Although less than a third of children and young people who subsequently died of cancer were referred to a SPPCS before death, referral was significantly associated with lower rates of planned hospital admissions in this cohort of children. The SPPCS clearly have a role in reducing hospital admissions during end of life care of paediatric cancer patients with potential personal, social and economic benefits.

\section{REFERENCES}

Basta N, James P, Gomez-Pozo B, Craft A, McNally R (2011) Survival from childhood cancer in northern England, 1968-2005. Br J Cancer 105: 1402-1408.

Census (2001) Office of National Statistics. Website: http://www.ons.gov.uk/ ons/rel/census/census-2001-key-statistics/local-authorities-in-englandand-wales/local-authorities-ks24-migration.xls (accessed on 1 March 2011).

Craft A, Killen S (2008) Palliative care services for children and young people in England: and independent review for the secretary of state for health. London: Department of Health England.

Department of Health (2008a) Better Care, Better Lives. London: Crown.

Department of Health (2008b) Commissioning Safe and Sustainable Specialised Paediatric Services: A famework of critical inetr-dependencies London: Crown.

Fraser LK, Miller M, Draper ES, McKinney PA, Parslow RC. on behalf of the Paediatric Intensive Care Audit Network (2011a) Place of death and palliative care following discharge from paediatric intensive care units. Arch Dis Child 96(12): 1195-1198.

Fraser LK, Miller M, McKinney PA, Parslow RC, Feltbower RG (2011b) Referral to a specialist paediatric palliative care service in oncology patients. Pediatr Blood Cancer 56(4): 677-680.

Hughes-Hallet T, Craft A, Davies C (2011) Palliative care funding review: creating a fair and transparent funding system. Available at: http:// www.palliativecarefunding.org.uk/PCFRFinal\%20Report.pdf (accessed: 18 February 2013).

Johnston DL, Nagel K, Friedman DL, Meza JL, Hurwitz CA, Friebert S (2008) Availability and use of palliative care and end-of-life services for pediatric oncology patients. J Clin Oncol 26(28): 4646-4650.

Knapp C, Thompson L (2012) Factors associated with perceived barriers to pediatric palliative care: a survey of pediatricians in Florida and California. Palliative Med 26(3): 268-274. 
Lewis I, Lenehan C (2012) Report of the Long Term Conditions, Disability and Palliative Care Subgroup. London: Children and Young People's Health Outcome Forum.

Magnani C, Pastore G, Coebergh JW, Viscomi S, Spix C, Steliarova-Foucher E (2006) Trends in survival after childhood cancer in Europe, 1978-1997: report from the Automated Childhood Cancer Information System project (ACCIS). Eu J Cancer 42(13): 1981-2005.

Martin House Childrens' Hospice (2012) Website: www.martinhouse.org.uk.(accessed: 1 August 2012).

National Centre for Health Outcomes Development (2009) Compendium of Clinical and Health Indicators User Guide: Annex 4: Crown Copyright.

National Institute for Health and Clinical Excellence (2005) Improving Outcomes in Children and Young People with Cancer London: NICE.

NCIN (2009) Cancer Incidence and Survival by Major Ethnic Group, England 2002-2006.

NHS Information Centre (2011) Hospital Episodes Statistics. Website: www.hesonline.nhs.uk.

Office for National Statistics (2005) Mortality Statistics Cause. Review of the Registrar General on deaths by cause, sex and age, in England and Wales.

Phillimore P, Beattie A, Townsend P (1994) Widening inequality of health in northern England, 1981-91. Br Med J 308(6937): 1125-1128.

Shah A, Diggens N, Stiller C, Murphy D, Passmore J, Murphy MFG (2011) Place of death and hospital care for children who died of cancer in England, 1999-2006. Eur J Cancer 47(14): 2175-2181.
Sloper P (2000) Predictors of distress in parents of children with cancer: A prospective study. J Pediatr Psychol 25(2): 79-91.

Sloper P, While D (1996) Risk factors in the adjustment of siblings of children with cancer. J Child Psychol Psychiatry 37(5): 597-607.

Steliarova-Foucher E, Stiller C, Lacour B, Kaatsch P (2005) International classification of childhood cancer, third edition. Cancer 103: 1457-1467.

Tang ST, Hung Y-N, Liu T-W, Lin D-T, Chen Y-C, Wu S-C, Hsu TH (2011) Pediatric end-of-life care for taiwanese children who died as a result of cancer from 2001 through 2006. J Clin Oncol 29(7): 890-894.

van Laar M, McKinney P, Stark D, Glaser A, Kinsey S, Lewis I, Picton S, Richards M, Norman P, Feltbower R (2012) Survival trends of cancer amongst the south Asian and non-south Asian population under 30 years of age in Yorkshire, UK. Cancer Epidemiol 36(1): e13-e18.

Wilkinson JR, Feltbower RG, Lewis IJ, Parslow RC, McKinney PA (2001) Survival from adolescent cancer in Yorkshire, UK. Eur J Cancer 37(7): 903-911.

This work is published under the standard license to publish agreement. After 12 months the work will become freely available and the license terms will switch to a Creative Commons AttributionNonCommercial-Share Alike 3.0 Unported License. 